\title{
In Vitro Development of Parthenogenetic Eggs: A Fast Ecotoxicity Test with Daphnia magna?
}

\author{
Olímpia Sobral, ${ }^{*}$ Carla Chastinet, ${ }^{*}$ António Nogueira,* Amadeu M. V. M. Soares, ${ }^{*} \dagger$ \\ Fernando Gonçalves, $\dagger$ and Rui Ribeiro*,1 \\ *Instituto do Ambiente e Vida, Departamento de Zoologia da Universidade de Coimbra, Largo Marquês de Pombal, 3004-517 Coimbra, \\ Portugal; and $\dagger$ Departamento de Biologia da Universidade de Aveiro, Campus Universitário de Santiago, 3800 Aveiro, Portugal
}

Received November 19, 1999

In the present study, the authors investigated and defined development stages of Daphnia magna eggs that could be potential endpoints for sublethal toxicity tests with in vitro parthenogenetic egg cultures. Such an "egg test" could be a cost-effective alternative to the classic 21-day test with $D$. magna. Three main stages of embryonic development were considered: release of the egg external membrane, release of the internal membrane, and separation of the caudal spine. The first embryonic stage was attained approximately $30 \mathrm{~h}$ after transfer of eggs from ovaries to the brood chamber (considered as time zero), the second stage at $48 \mathrm{~h}$, and the third stage at $68 \mathrm{~h}$. Embryonic development was considered completed with the caudal spine separation. Thereafter, juveniles were able to swim in the water column. Egg mortality, duration of each egg stage, egg diameter, and egg abnormalities were investigated as potential endpoints. In vitro tests were carried out with several toxicants (DBS, 3,4-DCA, cadmium, and copper) and with acid mine drainage, sensitivity generally being higher than with the accepted chronic 21-day test with D. magna. (1) 2001 Elsevier Science

Key Words: in vitro testing; test development; Daphnia magna; eggs; embryonic development.

\section{INTRODUCTION}

Despite the relatively short life span of Daphnia magna, chronic testing with this cladoceran is usually time consuming, a test duration of 21 days being recommended (Weber, 1991; OECD, 1995). The reproductive success, which depends on egg production and egg mortality, is the main endpoint in chronic tests with D. magna. The existence of aborted eggs is rarely reported, probably due to their small dimensions and lack of movement. Baird et al. (1991b) showed that embryos had higher sensitivity to several

${ }^{1}$ To whom correspondence should be addressed. Fax: + 351-239824226. E-mail: rui.ribeiro@zoo.uc.pt. toxicants than later stages. Adult female D. magna simultaneously have three main stages of parthenogenetic reproduction: oocyte production oocyte vitellogenesis (both occurring inside ovaries), and egg development (occurring inside the brood chamber) (Zaffagnini, 1987). After passage to the brood chamber, eggs develop independent of parental organisms and, thus, embryonic development can be continued in in vitro cultures, allowing direct exposure to toxicants without the brood chamber protection.

Under controlled conditions, at $20^{\circ} \mathrm{C}$, female D. magna release a new brood every 3 days. During this period, eggs inside the brood chamber pass through different developmental stages. These stages can be distinguished by morphological alterations, as described by Obreshkove and Fraser (1940), such as invaginations, constrictions, cephalic and abdominal appendage differentiation, and eye development. Some of the stages, however, are relatively close, and a microscope of high-resolution power is required to distinguish the small morphological details. Embryo-larval tests with fish have been successfully used as an accurate tool to predict sublethal effects (Dave, 1993; van Leeuwen, 1995; Solbé, 1993). Furthermore, such tests were found to be more cost-effective than whole-life cycle tests, with higher sensitivity and shorter exposure periods (Dave, 1993; McKim, 1985). Similar principles could be used to establish a novel test with D. magna parthenogenetic eggs. The main aims of this study were to establish easy-to-identify egg stages that could be potential endpoints for toxicity tests with in vitro cultures of D. magna parthenogenetic eggs, and to assess their sensitivity in comparison with the chronic 21-day test.

\section{MATERIALS AND METHODS}

\section{Test Animals and Culture Conditions}

D. magna eggs were obtained from females cultured in ASTM hard water (Weber, 1991) with an organic supplement (Baird et al., 1989) and fed daily with $5 \times 10^{5}$ cells $/ \mathrm{mL}$ 
of the green alga Selenastrum capricornutum. Cultures were maintained at $20 \pm 0.5^{\circ} \mathrm{C}$, with a 16:8 light:dark cycle. Only eggs from the third to fifth broods were used to initiate toxicity tests.

\section{Egg Staging}

Just after the release of the second, third, or fourth brood, females were transferred to individual flasks containing $100 \mathrm{~mL}$ of medium, and observed every $30 \mathrm{~min}$ until passage of eggs from the ovaries to the brood chamber. This event was considered to represent time zero of egg development. Three hours after time zero, females were transferred to a dissection microscope and eggs were removed by introducing a small pipet with ASTM hard water in the brood chamber, to create a slow flow of medium dragging the eggs to the microscope slide. Eggs were washed several times, successively adding and removing medium with a small pipet. The eggs were then transferred to $1 \mathrm{~mL}$ of ASTM hard water in individual wells of tissue culture plates. Egg development was followed, with 66 replicates, until the release of the first molt, using an inversion microsope. Mortality and abnormalities were registered.

\section{Toxicity Testing}

Four toxicants (an organochlorine pesticide, a surfactant, and two metals) were used to assess the sensitivity of D. magna eggs: 3,4-dichloroaniline (3,4-DCA, supplied by Aldrich-Chemie), dodecyl benzyl sulfonate (DBS, a $\mathrm{C}_{12}$ linear alkyl benzenesulfonate, supplied by Unilever), cadmium (as cadmium chloride, supplied by Merck), and copper (as copper sulfate pentahydrate, supplied by Merck). Furthermore, a complex effluent (AMD, acid mine drainage from an abandoned copper mine located in southeastern Portugal) with a low $\mathrm{pH}$ (2.9) and high concentrations of metals (in decreasing amounts: $\mathrm{Fe}, \mathrm{Al}, \mathrm{Zn}, \mathrm{Mn}, \mathrm{Cu}, \mathrm{Co}, \mathrm{Ni}, \mathrm{Cd}, \mathrm{Cr}$ ) (Lopes et al., in press) was also tested. Dissolution of 3,4-DCA ( $\left.20 \mathrm{mg} \mathrm{L}^{-1}\right)$ was done as described by Ribeiro et al. (1995). ASTM hard water was used as a control and dilution water. Tests were performed in 24-well tissue culture plates and eggs were exposed individually in $1 \mathrm{~mL}$ for each concentration. A minimum of five concentrations or dilutions and 12 replicates per concentration were used in each test. Toxicant concentrations were selected according to $\mathrm{LC}_{50}$ values to $D$. magna juveniles from the literature, to allow the comparison of sensitivities between eggs in in vitro tests and juveniles in classic lethal tests.

Stage duration, abnormalities, and lack of development of the eggs in all toxicity tests were checked every $30 \mathrm{~min}$ during 12-h periods: from ca. $6 \mathrm{~h}$ before the expected end of each stage (in optimal conditions) until $6 \mathrm{~h}$ after. In preliminary tests with DBS, a decrease in egg diameter was observed. Therefore, in the definitive DBS test, egg diameter was measured 2 hours after the beginning of the test. Egg mortality during the first embryonic stage in the AMD test was divided into three components: undeveloped eggs (eggs with a homogeneous and dark brown appearance), eggs with little development (egg mass retraction with visible external and internal membranes), and developed eggs before complete head differentiation (cephalic region slightly distinguishable from body region). To allow the comparison of sensitivities to the AMD sample between eggs in the in vitro test and juveniles in classic lethal tests, a 48-h acute test with D. magna neonates was also performed. Juveniles, 6 to $24 \mathrm{~h}$ old, from the third to fifth broods, were exposed to the same AMD sample and same dilutions $(1.56,3.13,6.25,12.5$, and $25 \%$ of the AMD effluent). Four replicates of five organisms per test vessel $(175-\mathrm{mL}$ beakers with $50 \mathrm{~mL}$ of water) were used for each dilution and for the control. Mortality, defined as lack of movement after gentle prodding, was recorded at $48 \mathrm{~h}$.

One-way ANOVAs, Tukey multiple comparison tests, and probit analysis (Finney, 1971; Zar, 1984) were performed to determine the lowest observed effective concentration (LOEC) median lethal concentration $\left(\mathrm{LC}_{50}\right)$, median effective dilution $\left(\mathrm{EDil}_{50}\right)$, and median lethal dilution $\left(\mathrm{LDil}_{50}\right)$ values.

\section{RESULTS}

\section{Egg Staging}

Three main phases of egg development were identified: release of the external membrane, release of the internal membrane, and separation of the caudal spine. Just after passage from ovaries to the brood chamber (time zero), a D. magna egg is homogeneous and dark brown. The egg periphery becomes lighter, due to mass retraction, and external and internal membranes become visible. Later, the cephalic region can be distinguished from the body region. Release of the external membrane, which is considered the end of the first egg stage, occurs $30 \mathrm{~h}$ after time zero $(\mathrm{SD}=1.5 \mathrm{~h})($ Fig. 1$)$. Then, the symmetry of the egg changes from radial to bilateral. Lateral protrusions corresponding to the antennas become visible. Two separate pink eyes appear in the cephalic region. Release of the internal membrane, which is considered the end of the second egg stage, occurs $48 \mathrm{~h}$ after time zero ( $\mathrm{SD}=1.0 \mathrm{~h}$ ) (Fig. 1). Thereafter, the pink eyes fuse to form a single black eye. The distal region of the antennas separates from the body, permitting some movement, especially when embryos are under a strong light exposure. Separation of the caudal spine and release of a thin cuticle covering the feeding apparatus occur $68 \mathrm{~h}$ after time zero $(\mathrm{SD}=1.0)$. This event, which is considered the end of the third egg stage, concludes egg development (Fig. 1). Thereafter, organisms present free movement and feeding capacity. The first molt occurs $104 \mathrm{~h}$ $(\mathrm{SD}=4.3 \mathrm{~h})$ after time zero (Fig. 1). 


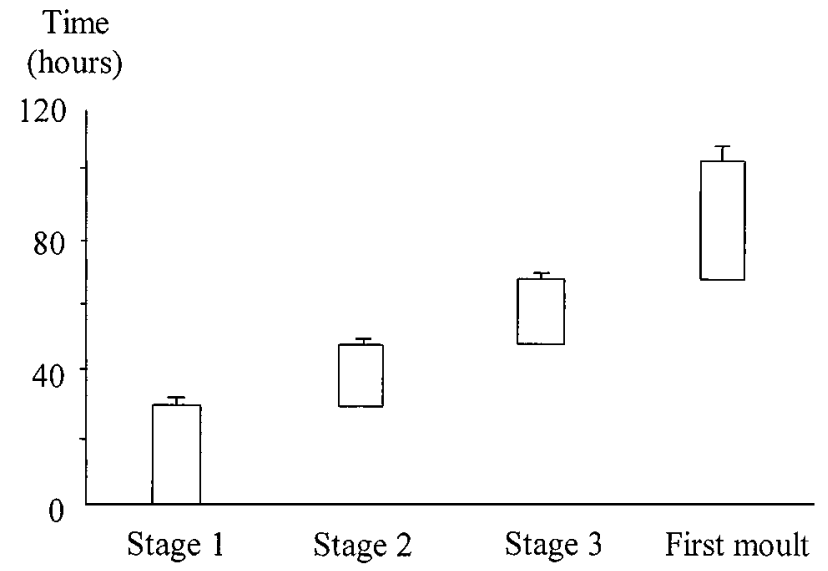

FIG. 1. Duration of each stage (mean and standard deviation) of egg development and time to the first molt of Daphnia magna $(n=66)$.

\section{Toxicity Testing}

Eggs exposed to 3,4-DCA presented a significant development delay in stage 1 (ANOVA: $F(5,57)=6.67, P=0.001$ ). The LOEC was the lowest 3,4-DCA concentration used $\left(\mathrm{LOEC}=0.625 \mu \mathrm{g} \mathrm{L}^{-1}\right)$. None of the eggs in the highest 3,4-DCA concentration $\left(40 \mu \mathrm{g} \mathrm{L}^{-1}\right)$ released the external membrane (Fig. 2). Among the eggs exposed to $20 \mu \mathrm{g} \mathrm{L}-1$ 3, 4-DCA, only one achieved complete development; the others did not release the external membrane. Nevertheless, the development of these eggs was not inhibited, resulting in abnormal neonates (Fig. 3).

Eggs exposed to DBS presented a significant development delay in stages 1,2 , and 3 (ANOVA: $F(2,29)=3.97$, $P=0.03 ; \quad$ ANOVA: $\quad F(2,34)=15.08, \quad P<10^{-3} ; \quad$ and ANOVA: $F(2,32)=16.22, P<10^{-3}$; respectively) (Fig. 4). The NOEC was the lowest DBS concentration

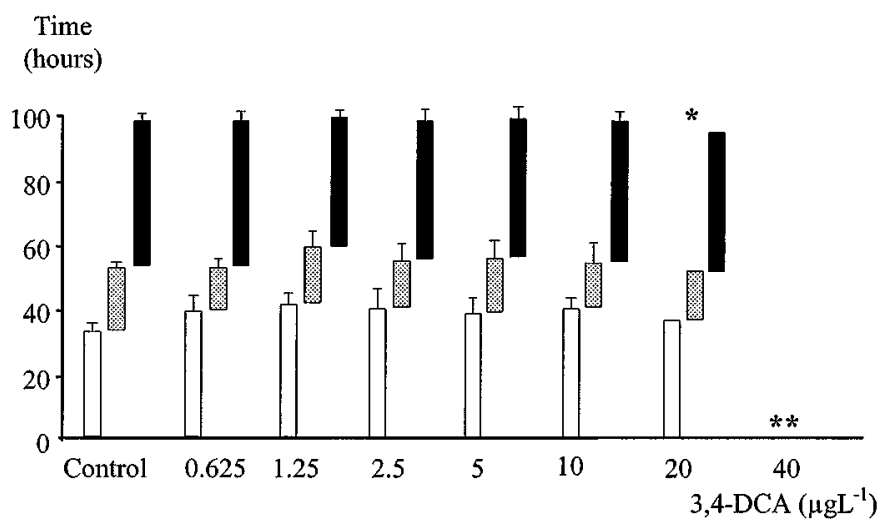

FIG. 2. Duration of stage 1 (white bars), stage 2 (gray bars), and stage 3 (black bars) (means and SD) of Daphnia magna eggs exposed to seven 3,4-DCA concentrations. *A single egg achieved complete development. **None of the eggs released the external membrane.

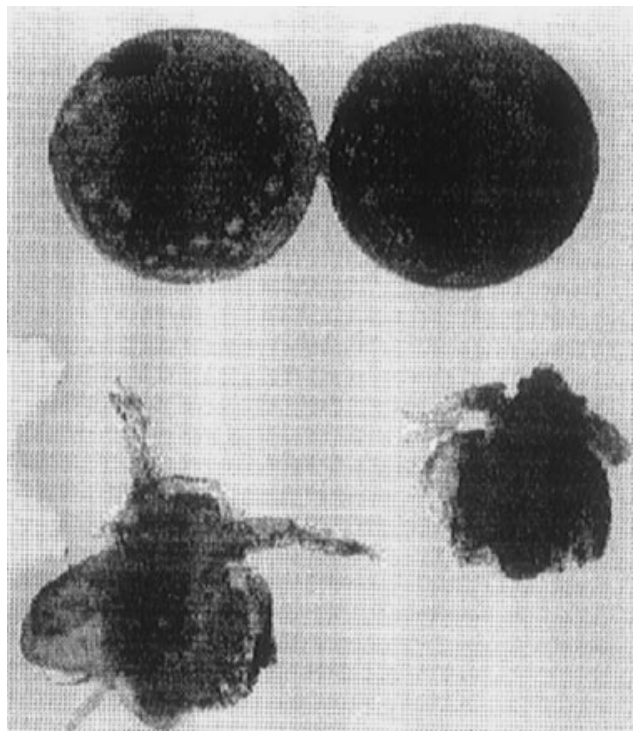

FIG. 3. Optical microscope photography of abnormal Daphnia magna eggs and juveniles exposed to $20 \mu \mathrm{g} \mathrm{L}^{-1} 3,4$-DCA.

(0.625 $\left.\mathrm{mg} \mathrm{L}^{-1}\right)$ and the LOEC corresponded to $1.25 \mathrm{mg} \mathrm{L}^{-1}$ DBS. Eggs exposed to the remaining concentrations died during the first stage without any visible development (eggs kept the homogeneous and dark brown appearance until the end of the test). The $\mathrm{LC}_{50}$ by the end of the test was $1.77 \mathrm{mg} \mathrm{L}^{-1}$ DBS. Eggs exposed for $2 \mathrm{~h}$ to DBS presented a significant decrease in diameter in the two highest concentrations (ANOVA: $F(7,93)=18.22$, $P<10^{-4}$ ) (Fig. 5).

Egg mortality increased with cadmium concentration and exposure time. None of the eggs in the highest cadmium concentration $\left(0.496 \mathrm{mg} \mathrm{L}^{-1}\right)$ released the external membrane (Fig. 6). The $\mathrm{LC}_{50}$ by the end of the test was $0.011 \mathrm{mg}$ $\mathrm{L}^{-1}$ (95\% confidence limits: $\left.0.0011-0.12 \mathrm{mg} \mathrm{L}^{-1}\right)$, being

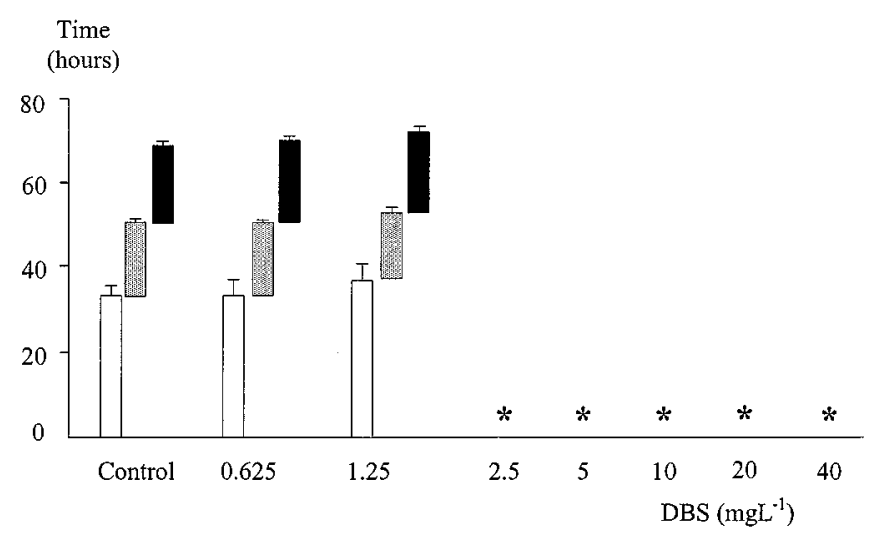

FIG. 4. Duration of stage 1 (white bars), stage 2 (gray bars), and stage 3 (black bars) (means and SD) of Daphnia magna eggs exposed to seven DBS concentrations. *None of the eggs released the external membrane. 


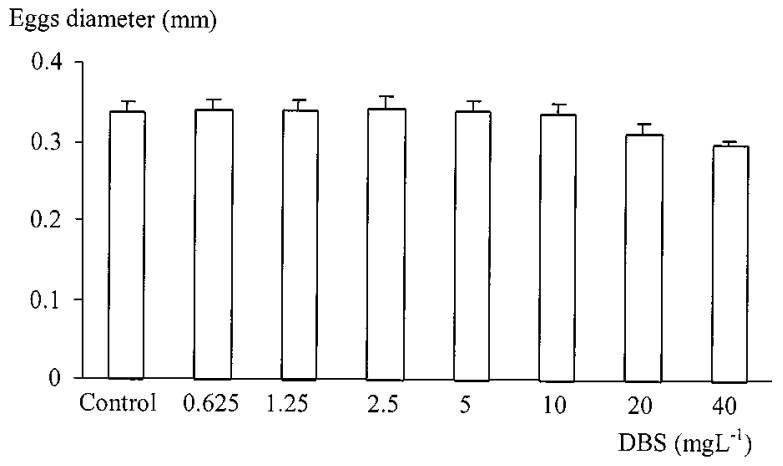

FIG. 5. Diameter of Daphnia magna eggs (means and SD) after $2 \mathrm{~h}$ of exposure to seven DBS concentrations.

below the lowest concentration $\left(0.031 \mathrm{mg} \mathrm{L}^{-1}\right)$. Significant development delays in the first stage (ANOVA: $F(4,36)=11.76, P=10^{-4}$ ) were registered in all cadmium concentrations comparatively to the control.

None of the eggs exposed to copper released the external membrane $(100 \%$ mortality), even in the lowest concentration $\left(24 \mu \mathrm{g} \mathrm{L}^{-1}\right)$. The eggs kept the homogeneous and dark brown appearance in all copper concentrations.

Conductivity $\left(550-561 \mu \mathrm{S} \mathrm{cm} \mathrm{cm}^{-1}\right), \mathrm{pH}(7.3-8.2)$, and dissolved oxygen $\left(8.4-8.7 \mathrm{mg} \mathrm{L}^{-1}\right)$ values of the five AMD dilutions $(1.57-25 \%)$ were similar to control values $(548 \mu \mathrm{S}$ $\mathrm{cm}^{-1}, \mathrm{pH} 8.1$, and $8.5 \mathrm{mg} \mathrm{L}^{-1}$ of dissolved oxygen). None of the eggs exposed to AMD dilutions released the external membrane (100\% mortality). Nevertheless, a gradient of egg differentiation was found among the dilutions tested (Fig. 7). The $\mathrm{EDil}_{50}$ for cephalic differentiation was to $3.47 \%(95 \%$ confidence limits: $2.35-5.13 \%$ ) (Fig. 7). In the classic acute test with D. magna neonates exposed to AMD effluent, the $\mathrm{LDil}_{50}$ at $48 \mathrm{~h}$ was found to be $2.3 \%$ (95\% confidence limits: $1.1-4.6 \%)$.

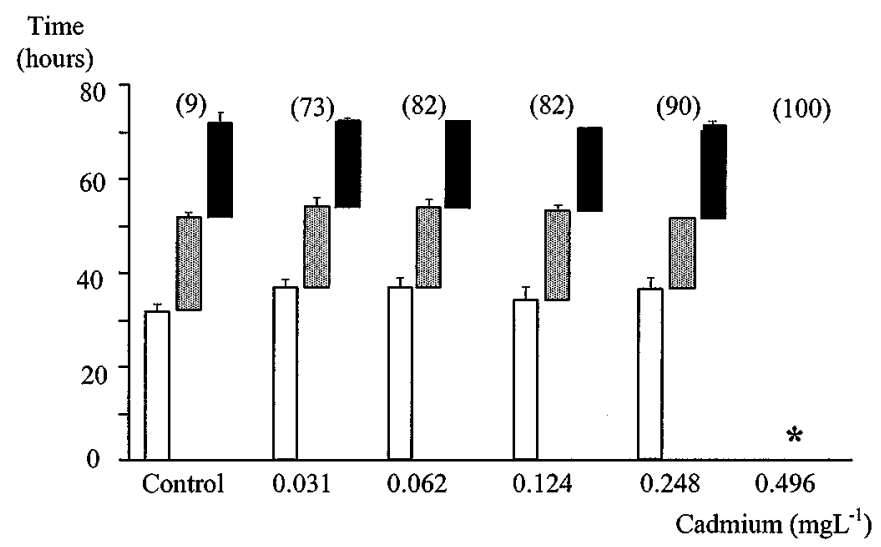

FIG. 6. Duration of stage 1 (white bars), stage 2 (gray bars), and stage 3 (black bars) (means and SD) of Daphnia magna eggs exposed to five cadmium concentrations. Egg mortality (\%) is given within parentheses. *None of the eggs released the external membrane.

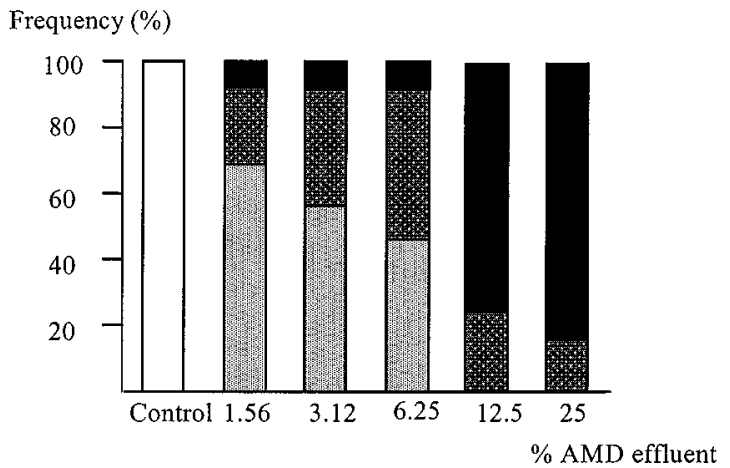

FIG. 7. Frequency of completely developed eggs (white bars), developed eggs before complete head differentiation (light gray bars), eggs with little development (dark gray bars), and undeveloped eggs (black bars) of Daphnia magna exposed to five dilutions of an acid mine effluent (AMD).

\section{DISCUSSION}

\section{Egg Staging}

Embryonic development of Daphnia is a continuous process, not separated by stages (Green, 1965). However, the reference to certain embryonic structures as stages is an easy way to explain the continuity of the process; i.e., if, with an optical microscope, it is possible to observe the presence of two pink eyes, then one knows that a high level of cellular differentiation had occurred until that moment, and, under standard conditions, a single black eye will be visible in a short period. Thus, several authors consider the existence of stages in physiological and ecological studies (Green, 1956; Murugan and Venkataraman, 1977; Guldbradsen and Johnsen, 1990; Ohta et al., 1998). In this study, D. magna embryonic development was divided into three long stages based on the release of egg membranes (release of the external membrane, release of the internal membrane, and caudal spine separation), to allow easy and fast identification, avoiding long light exposures under a dissecting microscope. Ohta et al., (1998) reported longer development periods for embryos exposed to $20 \mathrm{mg} \mathrm{L}^{-1}$ ethyllenethiourea when compared with controls. Those results reinforce the hypothesis that the period needed to reach the different stages under stress conditions could be used as a potential endpoint in toxicity testing. The duration of the juvenile first stage, from caudal spine separation until the first molt, was discarded as a toxicity endpoint because the variability associated with the time of first molt $(\mathrm{SD}=4.3)$ is very large when compared with other phase transitions. This large variability would imply an almost uninterrupted observation of organisms as soon they became juveniles.

During egg development, only two membranes were detected, which agreed with the observations made by Obreskove and Fraser (1940) for D. magna, by Lei and Clifford 
(1974) for D. schфdleri, and by Guldbradsen and Jonhsen (1990) for D. pulex. Esslova (1959 in Lei and Clifford, 1974) reported the existence of a third membrane involving the embryo. In the present study, the release of a thin cuticle was observed during extension of the caudal spine. This cuticle seems to cover the embryo feeding apparatus, preventing the entrance of water before complete embryonic development.

\section{Toxicity Testing}

Toxic effects of 3,4-DCA on D. magna reproduction have been reported by several authors (e.g., Diamantino et al., 1997; Elendt, 1990; Soares et al., 1992). Baird et al. (1991b) pointed out that this toxicant affects embryonic development, inside the brood chamber, more than egg production in female ovaries. Guilhermino et al. (1999) showed that it was possible to reduce chronic exposure to 3,4-DCA, from 21 to 10 days, with a similar final $\mathrm{EC}_{50}$ for D. magna reproduction. Being so, removal of eggs from the brood chamber would enhance their exposure to the toxicant and, thus, significant effects would be anticipated at lower 3,4-DCA concentrations. Indeed, such increased sensitivity was found in the present study: the LOEC value for the duration of the first egg stage $\left(0.625 \mu \mathrm{g} \mathrm{L}^{-1}\right)$ was much lower than LOECs reported in the literature for the $D$. magna reproduction test: 5-20 (Soares et al., 1990), 10 (Diamantino et al., 1997), 12 (Elendt, 1990), and (Guilhermino et al., 1999) $20 \mu \mathrm{g} \mathrm{L}^{-1}$.

LOECs of the surfactant DBS for the duration of egg stages 1,2 , and 3 found in the present study $\left(1.25 \mathrm{mg} \mathrm{L}^{-1}\right)$ were below the range of sublethal effects of $\mathrm{C}_{11.8}$ LAS (linear alkyl benzenesulfonate) in D. magna chronic testing (1.7-3.4 $\mathrm{mg} \mathrm{L}^{-1}$ ) reviewed by Lewis (1991). Lower values (0.025-0.05 $\mathrm{mg} \mathrm{L}^{-1}$ ) were reported by Malcolm et al. (1995) when marine invertebrate eggs or embryos (Crassostrea virginica, Mytilus edulis, and Paracentrotus lividus) were exposed to $\mathrm{C}_{12}$ and $\mathrm{C}_{13}$ LAS. The reduction in egg volume observed here for 20 and $40 \mathrm{mg} \mathrm{L}^{-1}$ DBS was an anticipated result due to the detergent action in lipid components (cellular membranes and lipid reserves). Dissolution and dispersion of lipids lead to retraction of the egg mass, preventing normal embryonic development. The $\mathrm{LC}_{50}$ value for egg mortality $\left(1.77 \mathrm{mg} \mathrm{L}^{-1}\right)$ was below the range of values reported for lethal toxicity of $\mathrm{C}_{11.8}$ LAS to D. magna and D. pulex $\left(4-7.1 \mathrm{mg} \mathrm{L}^{-1}\right)$ after $48 \mathrm{~h}$ of exposure (Maki and Bishop, 1979) and was within the large interval reported for freshwater invertebrates $\left(0.1-270 \mathrm{mg} \mathrm{L}^{-1}\right)$ (Malcolm et al., 1995).

The lethal response to cadmium observed in this study $\left(\mathrm{LC}_{50}=11 \mu \mathrm{g} \mathrm{L}^{-1}\right)$ was slightly lower than literature values for classic acute tests with D. magna exposed for $24 \mathrm{~h}$ $\left(17.7 \mu \mathrm{g} \mathrm{L}^{-1} \leq \mathrm{LC}_{50} \leq 88.6 \mu \mathrm{g} \mathrm{L}^{-1}\right.$ ) (Guilhermino et al., 1997). Mance (1990) reported higher $\mathrm{LC}_{50}$ values for $48 \mathrm{~h}$ of exposure than the $\mathrm{LC}_{50}$ found here when moderately hard water and soft water were used $\left(\mathrm{LC}_{50}=58\right.$ and $30 \mu \mathrm{g} \mathrm{L} \mathrm{L}^{-1}$, respectively). Bodar et al. (1989) reported a $\mathrm{LC}_{50}$ of $30 \mu \mathrm{g} \mathrm{L}^{-1}$ after $48 \mathrm{~h}$ of exposure for adult females (21 days old). The sensitivity of in vitro development of D. magna eggs to copper exposure $\left(100 \%\right.$ mortality at $\left.24 \mu \mathrm{g} \mathrm{L}^{-1}\right)$ was higher than the sensitivity of juveniles reported by other authors (Baird et al., 1991a; Biesinger and Christensen, 1972; Mance, 1990; Guilhermino et al., 1999: $\mathrm{LC}_{50}=10.5$, 60,87 , and $21 \mu \mathrm{g} \mathrm{L}^{-1}$, respectively). Thus, for both cadmium and copper, eggs exposed here were more sensitive than juveniles in D. magna acute tests reported in the literature. These findings do not corroborate the conclusion of Bodar et al. (1989) about the sensitivity to metals of early life stages of D. magna compared with later stages. In their study, the toxicity of $\mathrm{Zn}, \mathrm{Cu}, \mathrm{Cd}$, and $\mathrm{Pb}$ was assessed using in vitro cultures of parthenogenetic eggs, and early life stages were found to be more tolerant, which was explained by the protective function of egg membranes. A plausible explanation for this divergence is the duration of the tests; the last observation made by Bodar et al. (1989) was after $46 \mathrm{~h}$ of exposure, which corresponds approximately to internal membrane release. In our study, tests ended when control eggs achieved complete development, approximately $72 \mathrm{~h}$ after time zero.

The results obtained with eggs exposed to acid mine effluent were compared with those of an acute test performed with $D$. magna juveniles. The in vitro test presented $100 \%$ egg mortality during stage 1 at a dilution of $1.56 \%$ of the AMD, while the $\mathrm{LDil}_{50}$ for the juveniles was $2.3 \%$. Since $\mathrm{pH}$, conductivity, and dissolved oxygen in all tested dilutions $(1.56$ to $25 \%$ ) were very similar to those of the ASTM control, differences in sensitivity between eggs and juveniles were most probably due to the action of metal ions (mainly copper) on organisms, thus confirming results with copper and cadmium obtained in the present study.

\section{CONCLUSION}

Egg development of D. magna was divided into several easy-to-indentify stages and potential toxicity endpoints were investigated. These endpoints were significantly affected by exposure to toxicants in proportion to chemical concentrations and, thus, were potentially useful for the definition of concentration-response relationships. Several endpoints in this study were revealed to be more sensitive than classic D. magna tests for all tested chemicals: an organochlorine compound, a surfactant, two metals, and a complex industrial effluent. Although such an "egg test" can be viewed as a potential cost-effective alternative to the classic 21-day test with D. magna, caution is needed when extrapolating to the population level due the eventual under- or overestimation of potential effects. Similarly to other classic tests, namely, acute ones, relevant routes of exposure 
are enhanced (e.g., direct absorption of toxicants through the organism surface) and others even suppressed (entrance of toxicant adsorbed to food). More tests are needed to standardize toxicity endpoints and protocols. The choice of endpoints to be used should result from balancing effort and test time against sensitivity.

\section{ACKNOWLEDGMENT}

This work was partially funded by Junta Nacional de Investigação Científica e Tecnológica/Fundação para a Ciência e a TecnologiaPRAXIS XXI.

\section{REFERENCES}

Baird, D. J., Barber, I., Barber, M. C., Calow, P., and Soares, A. M. V. M. (1989). The Daphnia bioassay: A critique. Hydrobiologia 188/189, 403-406.

Baird, D. J., Barber, I., Bradley, M. C., Soares, A. M. V. M., and Calow, P. (1991a). A comparative study of genotype sensitivity to acute toxic stress using clones of Daphnia magna Straus. Ecotoxicol. Environ. Saf. 21, 257-265.

Baird, D. J., Barber, I., Soares, A. M. V. M., and Calow, P. (1991b). An early life-stage test with Daphnia magna Straus: An alternative to the 21-day chronic test? Ecotoxicol. Environ. Saf. 22, 1-7.

Biesinger, K. E., and Christensen, G. M. (1972). Effects of various metals on survival, growth, reproduction, and metabolism of Daphnia magna. J. Fish Res. Bd. Can. 29, 1691-1700.

Bodar, C. W. M., Zee, A. V. D., Voogt, P. A., Wynne, H., and Zandee, D. I. (1989). Toxicity of heavy metals to early life stages of Daphnia magna. Ecotoxicol. Environ. Saf. 17, 333-338.

Dave, G. (1993). Replicability, repeatability, and reproducibility of embryo-larval toxicity tests with fish. In Progress in Standardization of Aquatic Toxicity Tests (A. M. V. M. Soares and P. Calow, Eds.), pp. 129-157. Lewis, Boca Raton, FL.

Diamantino, T. C., Ribeiro, R., Gonçalves, F., and Soares, A. M. V. M. (1997). METIER (Modular Ecotoxicity Tests Incorporating Ecological Relevance) for difficult substances. 4. Test chamber for cladoceran in flow-through conditions. Environ. Toxicol. Chem. 16, 1234-1238.

Elendt, B.-P. (1990). Influence of water composition on the chronic toxicity of 3,4-dichloroaniline to Daphnia magna. Water. Res. 24, 1169-1172.

Finney, D. J. (1971). Probit Analysis, 3rd ed. Cambridge Univ. Press. Cambridge, UK.

Green, J. (1956). Size and reproduction in Daphnia magna. Proc. Zool. Soc. London 126, 428-436.

Green, J. (1965). Chemical embryology of the crustacea. Biol. Rev. 40, 580-600.

Guilhermino, L., Diamantino, T. C., Ribeiro, R., Gonçalves, F., Silva, M. C., and Soares, A. M. V. M. (1997). Suitability of test media containing EDTA for the evaluation of acute metal toxicity to Daphnia magna Straus. Ecotoxicol. Environ. Saf. 38, 292-295.

Guilhermino, L., Sobral, O., Chastinet, C., Ribeiro, R., Gonçalves, F., Silva, M. C., and Soares, A. M. V. M. (1999). A Daphnia magna first-blood chronic test: An alternative to the conventional 21-day chronic bioassay? Ecotoxicol. Environ. Saf. 42, 67-74.

Guldbradsen, J., and Johnsen, G. H. (1990). Temperature-dependent development of parthenogenetic embryos in Daphnia Pulex de Geer. J. Plankton Res. 12, 443-453.

Lei, C., and Clifford, H. F. (1974). Field and laboratory studies of Daphnia schødleri Sars from a Winterkill a lake of Alberta. Nat. Mus. Can. Zool. Publ. 9, 1-53.

Lewis, A. (1991). LAS. Water Res. 25, 101-113.

Lopes, I., Gonçalves, F., Soares, A. M. V. M., and Ribeiro, R. (1999). Discriminating the ecotoxicity due to metals and to low $\mathrm{pH}$ in acid mine drainage. Ecotoxicol. Environ. Saf. 44, 207-214.

Maki, A. W., and Bishop, W. E. (1979). Acute toxicity studies of surfactants to Daphnia magna and Daphnia pulex. Arch. Environ. Contam. Toxicol. 8, 599-612.

Malcolm, H. M., Howe, P. D., and Dobson, S. (1995). Toxicity of LAS to aquatic organisms. TEN 2, 20-24.

Mance, G. (1990). Pollution Threat of Heavy Metals in Aquatic Environments. Elsevier, London.

McKim, J. M. (1985). Early life stage toxicity tests. In Fundamentals of Aquatic Toxicology (G. M. Rand and S. R. Petrocelli, Eds.), pp. 58-95. Hemisphere, Washington, DC.

Murugan, N., and Venkataraman, K. (1977). Study of the in vitro development of the parthenogenetic egg of Daphnia carinata King (Cladocera: Daphnidae). Hydrobiologia 52, 129-134.

Obreshkove, V., and Fraser, A. W. (1940). Growth and differentiation of Daphnia magna eggs in vitro. Biol. Bull. 78, 428-436.

OECD (1995). Test Guideline Program. Draft Report of the Final Ring Test of the Daphnia magna Reproduction Study. OECD, Paris.

Ohta, T., Tokishita, S., Shiga, Y., Hanazato, H., and Yamagata H. (1998). An assay for detecting environmental toxicants with cultured cladoceran eggs in vitro: Malformations induced by ethylenethiourea. Environ. Res. A 77, 43-48.

Ribeiro, R., Lima, L. M., Gonçalves, F., and Soares, A. M. V. M. (1995). METIER (Modular Ecotoxicity Tests Incorporating Ecological Relevance) for difficult substances: Aedes aegypti (Diptera, Culicidae) initial module test development using 3,4-dichloroaniline. Environ. Toxicol. Chem. 14, 1241-1246.

Soares, A. M. V. M., Baird, D. J., and Calow, P. (1992). Interclonal variation in the performance of Daphnia magna Straus in chronic bioassays. Environ. Toxicol. Chem. 11, 1477-1483.

Solbé, J. (1993). Freshwater fish, In Handbook of Ecotoxicology (P. Calow, Ed.), Vol. I, pp. 66-82. Blakwell Scientific, Oxford.

van Leeuwen, C. J. (1995). Ecotoxicological effects. In Risk Assessment of Chemicals: An Introduction (C. J. van Leeuwen and J. L. M. Hermens, Eds.), pp. 175-237. Kluwer Academic, Dordrecht.

Weber, C. I. (Ed.) (1991). Methods for Measuring the Acute Toxicity of Effluents to Freshwater and Marine Organisms, EPA/600/4-90-027. U.S. Environmental Protection Agency, Cincinnati, OH.

Zaffagnini, F. (1987). Reproduction in Daphnia. Mem. Ist. Ital. Idrobiol. 45, 245-284.

Zar, J. H. (1984). Biostatistical Analysis, 2nd ed. Prentice-Hall, Englewood Cliffs, NJ. 